\title{
ФРАЗЕОЛОГИЧЕСКИЕ ОБОРОТЫ И ИХ ВЛИЯНИЕ НА ЛИЧНОСТНОЕ АKME
}

\section{PHRASEOLOGICAL EXPRESSIONS AND THEIR INFLUENCE ON PERSONAL ACME \\ A. Gerasimova K. Skripnik}

Summary: The contents of the article reflect the central concept of phraseology - phraseological expressions and their significance in reaching the peak of creative maturity of the individual. The vocabulary analysis of A.V. Kunin's dictionary was carried out by the method of continuous sampling to identify phraseological units. These lexical phrases are able to convey the process of acquiring knowledge and achieving personal acme. The fundamental archisemes included in the acme are the English lexical units "know", "skill" and "trade".

Keywords: phraseology, semantics, phraseological expressions, acmeology, acme, archiseme.
A нализ современных исследовательских работ позволяет говорить о том, что во многих из них предметом изучения и описания являются фразеологические единицы. Интерес к центральному понятию фразеологии - фразеологическому обороту - обусловлен наличием национальных культурно-специфических и структурно-языковых особенностей, присущих данным единицам.

Существенный вклад в развитие фразеологии сделали отечественные лингвисты: В.В. Виноградов [2], В.П. Жуков [3], А.В. Кунин [4], Н.М. Шанский [7], А.И. Молотков [5] и многие другие исследователи.

Семантическое и формальное своеобразие сочетаний слов, образующих фразеологический оборот, привлекает внимание лингвистов и позволяет выделить в исследовании фразеологизмов такие по-прежнему проблемные вопросы, как семантическая и формальная устойчивость фразеологизмов, стилистическая принадлежность фразеологизмов, этимологическая характеристика фразеологизмов, частеречная характеристика компонентов, входящих во фразеологизм, раздельнооформленность фразеологизмов, эквивалентность фразеологизма слову, объем фразеологии, методы изучения фразеологизмов, эквивалентность разноязычных фразеологизмов, методика перевода фразеологизмов [7, с.89].

Английская фразеология присутствует в качестве предмета изучения в большом количестве исследова-
Герасимова Анна Валерьевна

К.филол.н., доцент, Московский государственный областной университет

Annagsm777@gmail.com

Скрипник Ксения Васильевна

К.филол.н., доцент, Московский государственный областной университет

Montn@yandex.ru

Аннотация: Содержание статьи отражает центральное понятие фразеологии - фразеологические обороты и их значение в достижении вершины творческой зрелости личности. Методом сплошной выборки был проведен анализ вокабуляра словаря А.В. Кунина по выявлению фразеологических единиц. Выбранные лексические обороты своим значением способны передать процесс приобретения знаний и достижение личностного акме. Основополагающими архисемами включенными в акме, выступают английские лексические единицы «know», «skill», «trade».

Ключевые слова: фразеология, семантика, фразеологические обороты, акмеология, акме, архисема.

ний, в результате которых установлено, что английская фразеология отличается богатством и разнообразием фразеологических единиц, национальная самобытность которых создает определенные трудности в переводе с английского языка на другие.

Русский и английский языки, имея каждый свою собственную фразеологию, способны отразить посредством устойчивых единиц особенности своей национальной культуры, особенности своего национального общественного мышления.

Многочисленными работами, посвященными изучению фразеологии, доказано, что в каждой национальной фразеологии найдутся устойчивые сочетания слов, обладающие способностью обозначить любое явление человеческой жизни. В качестве языкового материала, способного своим значением указать на характеристику языковой личности, достигающей акме, выступают не только словесные единицы, но и фразеологические сочетания. Термином акме определяется феномен вершины творческой зрелости личности при самоактуализации человека в гражданской, личностной, межличностной, профессиональной, духовной, семейной и других ипостасях жизнедеятельности [1, с.43].

Составными компонентами акме являются приобретенные знания, умения и мастерство. В соответствии с ними выделяются тематические группы фразеологических единиц «знание», «умение», «мастерство». 
Методом сплошной выборки был проведен анализ вокабуляра словаря А.В. Кунина [4] по выявлению тех фразеологических оборотов, которые своим значением способны передать процесс получения знания.

\section{Тема «знания»}

Согласно словарю С.И. Ожегова, знание - «1. Знать. 2. Результаты познания, научные сведения. 3. Совокупность сведений в какой-нибудь области» [6, с. 235].

Знания - это система понятий о предметах и явлениях, усвоенных в результате восприятий аналитико-синтетического мышления, запоминания и практической деятельности личности.

Архисемой фразеологических единиц, включенных в группу «знания», является английское слово "know" знание. Глубина знаний определяется проникновением в сущность и знанием всех элементов предметов и явлений.

Анализ вокабуляра словаря А.В. Кунина позволил выделить такие английские фразеологические обороты и их примеры из самого словаря:

"Know smb. (или smth.) as one knows his ten fingers (тж. know smb. или smth. tike the back или palm of one's hand, ycm. as well as beggar knows his dish)" - прекрасно знать кого-либо или что-либо; знать кого-либо или что-либо как свои пять пальцев. "He knew his assets and his liabilities as he knew his ten fingers"- Он прекрасно знал состояние своего актива и пассива [4, с. 430].

"Be on the inside" - быть в курсе дела, знать все подробности. "Lanny could talk a lot about that and he found himself an important person, having been on the inside, and knowing things which the papers didn't tell" - O6 этом Ланни мог многое порассказать, и все внимали ему с благоговением; еще бы, ведь он видел все это изнутри, он знал то, о чем не писали в газетах [4, с. 411].

"Know the ropes" - досконально знать, быть в курсе дела, разбираться хорошо, хорошо ориентироваться; знать все входы и выходы. "Mr, Twigg", he cried, addressing Mr. Golspie, "and Mr. Dersingham" you can rely on me. I know the people. I know the ropes, if you don't mind me saying so" - Мистер Твигт! — воскликнул он (обращаясь к мистеру Голспи), - и мистер Дерсингем! Вы можете на меня положиться! Я дело знаю. Я знаком с нужными людьми. Я, если позволите так выразиться, на этом собаку съел. [4, с. 642].

"Know twists and turns" - знать тонкости, детали, подробности. "He knows the twists and turns of the British laws," - Он искушен в тонкостях английских законов [4, с. 783].
"A Daniel comes to judgement " - мудрый человек. "...l recommend the settlement." "Bunting, you're on the beam. A Daniel comes to judgment" - Рекомендую заключить эту сделку. Бантинг, вы дали очень дельный совет, вы человек мудрый [4, с. 195].

"As solemn (или wise) as an owl" - мудрый как сова. " Hope looked at the three middle- aged men, who were as solemn as owls... and shook with laughter, « - Хоуп взглянула на этих мужчин уже не первой молодости и залилась смехом: все трое глубокомысленно таращили глаза — ну точь-в-точь филины... [4, с. 557].

"No man is born wise or learned" - мудрецом и ученым не рождаются [4, с. 484].

"No man is wise at all times" - на всякого мудреца довольно простоты, на всякий час ума не напасешься [4, C. 484].

"Speak by the book" - говорить с уверенностью, утверждать что-либо на основании твердых знаний. "Carrie's nuts about this Russian revolution. Is there much to it, Perce?" "There is not! I can speak by the book there... I got it from a man who's close to the State Department, but as a matter of fact the Czar will be back in power before the end of the year," - Кэрри увлекается этой русской революцией. Тамошние события действительно имеют большое значение, Перси? Никакого!.. Тут я могу говорить с уверенностью... Я узнал об этом от человека, близкого к государственному департаменту. Могу сказать вам, что царь еще до конца года вернется к власти [4, с. 99].

"Speak (или talk) like a book" - говорить ученым, книжным языком. "What would be the good of such things to me if I knew that I... violated my instincts?" "You talk like a book - you talk like a book", muttered the old gentleman. Какая будет от этого польза, если я знаю, что... пошел против собственных инстинктов? - Мудрено что-то говорите, мудрено, - пробормотал старый джентльмен [4, с. 99].

"A nodding acquaintance ( with smth.)" - поверхностное знакомство с чем-либо. "Of course", I have only a nodding acquaintance with your dashing activities, my dear Lewis said Rose... - Конечно, я лишь поверхностно знаком с вашей бурной деятельностью, мой дорогой Льюис, - сказал Роуз... [4, с. 28].

"Have a bad ( или no) head for smth" - плохо разбираться в чем-либо. Fotheringham said: “... I have no experience and no head for figures. " - ...У меня нет опыта, и я плохо запоминаю цифры, - сказал Фотерингем [4, с. 367].

"Knowledge is power" — «знания - сила»."...with knowledge you can face up to anything, for knowledge is power," - ... когда овладеешь знаниями, ничего не страшно. 
Ведь знания - сила [4, с. 431].

"Show one's paces" - проявить способности, знания. "Katharine was determined to show her paces as a housewife and win their confidence," - Катарина была полна решимости показать золовкам, какая она прекрасная домашняя хозяйка; ей хотелось завоевать их расположение $[4$, с. 559].

Анализ вокабуляра словаря А.В. Кунина показал, что тема «знания» представлена достаточно широко. Выявлено 14 устойчивых сочетаний английских слов, которые способны передать данное значение.

При этом следует заметить, что не все фразеологические обороты содержат в своей структуре формальный компонент - архисему "know" - знание. Следовательно, общее значение фразеологизмов, рассматриваемых в данной группе, не зависит от формального присутствия в них лексемы "know" - знание.

\section{Тема «умение»}

Согласно словарю С.И. Ожегова, умение - это «способность делать что-нибудь, приобретенная знанием, опытом» [6, с. 830].

Умение - это способность человека продуктивно с должным качеством и в соответствующее время выполнять работу в новых условиях.

В результате компонентного анализа выделена архисема "skill" - умение - сема родового значения, выражающая идею умения в целом.

В словаре А.В. Кунина обнаружены следующие английские устойчивые сочетания слов, значение которых может быть соотнесено со значением "skill" - умение:

"To be quick on the draw" - быстро соображать, не теряться." Hе was a strong, forceful bull-like youth quick on the draw with wit when talking about jazz and woman, but dense on such mathematical subjects and cartography," Билл был здоровенный как бык, мог поговорить о джазе или о женщинах, но в точных науках ничего не смыслил $[4$, c. 225].

"Have (got) one's head screwed on right (или the right way)" - иметь голову на плечах, быть смышленым, сообразительным. Mrs. Bessie had her head screwed on the right way, there was no denying it, although why she married Ted Watt no one could imagine- - Нельзя отрицать, что миссис Бесси - женщина с головой, хотя и непонятно, как она могла выйти замуж за Теда Уотта [4, с. 368].

"Have a way (with smb или smth)" - уметь обращаться, иметь подход к чему-либо. Machiavelli knew very well that, as for himself, he had a way with women...- Макиавелли прекрасно понимал, что умеет очаровывать женщин... [4, с. 805].

"Bedside manner" - умение обращаться с больным, врачебный такт. "There was a peculiar charm in his manner, a mingling of gravity and kindliness, which was infinitely attractive." "You've got a wonderful bedside manner", Philip murmured, closing his eyes with a smile," - У него была какая-то подкупающая манера говорить - озабоченный и в то же время мягкий тон. Филипу сосед казался чрезвычайно милым. «Вы умеете найти подход к больному», - сказал Филип с улыбкой, закрывая глаза [4, с. 486].

"As clean as a whistle" - очень ловко. "Well, they sure worked fast. It's cleaned out stick as a whistle", - Да, ничего не скажешь. Воры работали быстро. Обчистили дом со знанием дела [4, с. 819].

"A master of fence" - искусный спорщик. "The Sophists were cunning masters of fence" - Софисты были искушены в словесных баталиях [4, с. 492].

"Look through ( или see far into) a millstone" - обладать необыкновенной проницательностью. "Well, I 'd hold a wager there will be a Match between her and Dick Dolt: and I believe I can see as far into a Millstone as another Man," Держу пари, что Дик Долт и она поженятся. Я не менее проницателен, чем любой другой [4, с. 502].

Проведенный анализ словаря А.В. Кунина дает право говорить о том, что значение "skill" - умение представлено в количестве 7 английских устойчивых сочетаний слов.

При этом следует заметить, что все фразеологические обороты, включенные нами в данную группу, в своей формальной структуре не содержат компонент "skill"-уменuе.

\section{Тема «мастерство»}

В словаре С.И. Ожегова слово «мастерство» снабжено двумя значениями: мастерство - это «1. умение, владение профессией, трудовыми навыками, 2. высокое искусство в какой-нибудь области» [6, с. 343].

Мастерство - это высший уровень развития профессиональных умений и конечная цель профессионального обучения. Это легкость точного, творческого и быстрого выполнения работы. Архисемой фразеологических единиц, включенных в группу «мастерство», является английское слово "trade", имеющее значение «занятие», «профессия», «ремесло».

В словаре А.В. Кунина значение «мастерство» пред- 
ставлено такими английскими сочетаниями слов:

"A crack (good, great или rare) hand at smth" — мастер своего дела; умелец, искусник, золотые руки. "I am a great hand at inventing things," - Я большой любитель изобретать разные вещи [4, с. 347].

"Jack of all trades" - мастер на все руки. "...we had the smartest, most loyal coachman, handyman, Jack of all trades you ever saw, " - ...у нас был кучер - прекрасный работник и верный слуга. К тому же мастер на все руки. Другого такого не сыщешь [4, с. 413].

"Have one's head examined" - пройти проверку своих умственныхспособностей. "Anyone who votes for Nixon ought to have his head examined," - У того, кто голосует за Никсона, явно с головой не все в порядке [4, с. 368].

"To go to town" - умело и быстро работать, действовать со знанием дела. "The engineers really went to town on those plans," - Инженеры великолепно воплотили в жизнь этот проект [4, с. 774].

"Better fed than taught" - вырос, а ума не скопил; велика фигура, да дура. "As for the information possessed by those depends of the Abbacies, they might have been truly said to be better fed than taught, even though their fare had been worse than it was [Chesterton], " - Что касается образованности монастырских ленников, то надо отдать им должное: упитанностью они отличались больше, чем ученостью, хотя пища их была весьма скудной [4, с. 79].

"Come to one's senses (или to reason)" - образумиться, взяться за ум, опомниться. "And we've got to save a bit if we are going to live here until whoever decides the income tax come to the," - Если мы останемся жить здесь, то придется экономить, пока не возьмутся за ум те, кто вводит подоходный налог [4, с. 165].

"Teach one's grandmother to suck eggs" - учить, поучать старших; учить кого-либо делу, которое он хорошо знает; учить ученого. "There's always about a million young women just out of college who want to teach their grandmothers how to suck eggs" - Их миллион, этих молодых женщин, только что окончивших колледж и желающих учить своих бабушек уму-разуму [4, с. 330].

Проведенный анализ словаря А.В. Кунина дает право говорить о том, что значение, вербализованное русским словом «мастерство», представлено в количестве 7 английских устойчивых сочетаний слов.

Метод сплошной выборки анализа вокабуляра англорусского фразеологического словаря А.В. Кунина с целью выявления фразеологизмов, способных охарактеризовать получение языковой личностью знаний, навыков и умений, способствующих достижению акме, позволяет говорить о том, что достижение акме характеризуется приобретением языковой личностью определенных параметров неразрывно связанных между собой. Процесс отбора фразеологических единиц осложнялся тем, что, как известно, особенностью семантики фразеологического оборота является его многозначность, позволяющая соотносить фразеологизм с двумя и более денотатами. Приведенные фразеологические единицы, являются составными компонентами, непосредственно влияющими на личностное акме.

\section{ЛИТЕРАТУРА}

1. Бодалев А.А. Вершина в развитии взрослого человека: характеристики и условия достижения. М.: Изд. «Флинта», Изд. «Наука», 1998.168 с.

2. Виноградов В.В. Лексикология и лексикография: избранные труды М.: Наука, 1977. 312 с.

3. Жуков В.П. Семантика фразеологических оборотов. М.: Просвещение, 1978.160 с.

4. Кунин А.В. Большой англо-русский фразеологический словарь. М.: «Русский язык», 1984. 944 с.

5. Молотков А.И. Основы фразеологии русского языка. М.: Наука, 1977. 282 с.

6. Ожегов С.И. Словарь русского языка/ Под ред. Н.Ю. Шведовой, 22-е изд. М: Русский язык, 1990. 924 с.

7. Шанский Н.М. Лексикология современного русского языка. М.: Книжный дом «Либроком», 2009. 312 с.

(с Герасимова Анна Валерьевна (Annagsm777@gmail.com), Скрипник Ксения Васильевна (Montn@yandex.ru).

Журнал «Современная наука: актуальные проблемы теории и практики» 